\title{
Persistence of coronavirus disease 2019 (COVID-19) in patients with end-stage renal disease; an unrecognized phenomenon?
}

\author{
Macaulay Amechi Chukwukadibia Onuigbo $\mathbf{o}^{1,2} \bullet$ \\ ${ }^{1}$ The Robert Larner, M.D. College of Medicine, University of Vermont, Burlington, VT, USA \\ ${ }^{2}$ College of Business, University of Wisconsin MBA Consortium, Eau Claire, WI, USA
}

\section{A R T I C L E I N F O}

Article Type:

Case Report

\section{Article History:}

Received: 1 June 2020

Accepted: 7 June 2020

Published online: 19 June 2020

\section{Keywords:}

Coronavirus disease 2019

(COVID-19), End-stage renal disease,

Hemodialysis, Reverse transcription

polymerase chain reaction (RT-PCR)

test, Acute kidney injury

\begin{abstract}
A B S T R A C T
Since the global coronavirus disease 2019 (COVID-19) pandemic hit most parts of the world, the nephrology community has primarily focused on the associated incidence of often severe acute kidney injury (AKI) with the disease pandemic. For patients on maintenance in-center outpatient hemodialysis, the primary concern has been on prevention of the spread of COVID-19 among this vulnerable patient group. Our recent experience with one end-stage renal disease (ESRD) patient early in the Spring of 2020 has led us to speculate that ESRD patients may well exhibit an unusually prolonged period of persistence of COVID-19. This may explain the recent report of the unanticipated demonstration of a high rate of positive COVID-19 antibody testing among the staff of a Pediatric Outpatient Hemodialysis Unit in New York. Further studies are mandated as these investigations would help guide the implications of preventative measures against the spread of COVID-19 among both patients and staff of hemodialysis units around the world.
\end{abstract}

Implication for health policy/practice/research/medical education:

Since the emergence of the global pandemic of coronavirus disease 2019 (COVID-19), the attention of nephrologists and critical care physicians has centered around the associated incidence of acute kidney injury, sometimes requiring renal replacement therapy, and the devastating impact on ICU admissions and patient mortality. Generally, the duration of positive reverse transcription polymerase chain reaction (RT-PCR) tests of nasopharyngeal swabs among patients with COVID-19 is usually less than 14 days. Our recent experience with one ESRD patient early in the Spring of 2020 has led us to speculate that ESRD patients may well exhibit an unusually prolonged period of persistence of COVID-19. If confirmed, this would lead to major paradigm shifts in continued vigilance to mitigate COVID-19 spread within hemodialysis units around the world.

Please cite this paper as: Onuigbo MAC. Persistence of coronavirus disease 2019 (COVID-19) in patients with end-stage renal disease; An unrecognized phenomenon? J Renal Inj Prev. 2021; 10(1): e07. doi: 10.34172/jrip.2021.07.

\section{Introduction}

Since the emergence of the global pandemic of coronavirus disease 2019 (COVID-19), a lot of attention has centered around the incidence of acute kidney injury (AKI), sometimes requiring renal replacement therapy, and the devastating impact of AKI on patient mortality (1). In a recent report from China, in a cohort of 66 patients who recovered after treatment, $28(42.4 \%)$ women and 38 (57.6\%) men, median age of 44.0 (34.0-62.0) years, the median time from the onset of symptoms to first negative RT-PCR results for oropharyngeal swabs in convalescent patients was 9.5 (6.0-11.0) days (2). Our recent experience with one anuric end-stage renal disease (ESRD) patient early in the Spring of 2020 has led us to speculate that ESRD patients may well exhibit an unusually prolonged period of persistence of COVID-19. If confirmed, this would lead to major paradigm shifts in continued vigilance to mitigate COVID-19 spread within hemodialysis units around the world.

\section{Case Report}

In the Spring of 2020, one of our ESRD patients on thrice-weekly in-center outpatient chronic maintenance hemodialysis contracted COVID-19 infection following person-to-person transmission while a resident of a local nursing and rehabilitation center. His vascular 
access for hemodialysis is a left upper arm AV fistula. Another resident of the center had developed symptoms of COVID-19, was diagnosed promptly and was admitted to the hospital. As a preventative measure, all the other residents of the nursing and rehabilitation center were consequently screened after counseling and education by a multi-disciplinary team led by the attending physician of the nursing and rehabilitation center.

Our patient is a 79-year old obese male patient with multiple comorbidities including ischemic cardiomyopathy, atrial fibrillation on warfarin and sleep apnea on CPAP (continuous positive airway pressure). He only had a non-productive cough, no fever, no sorethroat, no headache, no difficulty breathing and no other systemic symptoms. His screening nasopharyngeal swab RT-PCR (reverse transcription polymerase chain reaction) test was positive for COVID-19 in late March 2020. Initially, as an outpatient, he had continued his hemodialysis in an isolated secure COVID-19-cohort hemodialysis subunit. All the staff who had contact with the patient donned non-reusable fitted N95 masks, face shields, gowns and gloves. These personal protective equipment (PPE) protocols are based on United States Centers for Diseases Control guidelines for TransmissionBased Precautions for patients with COVID-19 (3).

He was soon admitted to hospital due to the need for a negative-pressure room for safe CPAP management. During the hospital admission, he exhibited fevers $\left(38.4^{\circ} \mathrm{C}\right)$ and myalgias. He also completed a course of hydroxychloroquine and doxycycline during this hospitalization while he continued thrice-weekly hemodialysis in the isolated hospital room. A repeat nasopharyngeal RT-PCR test, the second such test, 22 days after the first positive test, while he was still an inpatient in the hospital, remained positive. He was discharged after 24 days in the hospital. He then continued outpatient hemodialysis in the isolated secure COVID-19-cohort hemodialysis subunit. A third nasopharyngeal RT-PCR test carried out 32 days from the first positive COVID-19 test, now as an outpatient, returned negative. A fourth test, repeated the day after, remained negative. He thereafter returned to the regular outpatient in-center hemodialysis unit while still wearing a mask during his hemodialysis treatments. This practice strictly followed the guidelines of the US CDC guidance of two negative RT-PCR tests, $>24$ hours apart, for re-entry to the regular hemodialysis unit (4). Ordinarily, it must be acknowledged that all our in-center outpatient hemodialysis patients wear surgical masks all the time from the time of arrival at the unit until they depart from the unit after hemodialysis; this again according to US CDC guidelines.

\section{Conclusion}

COVID-19 RNA has been demonstrated in human urine samples, a clear evidence of the urine being a probable means of excretion of viral particles in infected patients $(2,5)$. In the study by Ling et al from Shanghai, China, even though viral nucleic acid was found in urine in only four (6.9\%) patients out of 58 cases, furthermore viral RNA was present in urine specimens after throat swabs were negative (2). Indeed, in another publication, a case report, a 15-year old asymptomatic female patient exhibited a negative throat swab RT-PCR test whereas the urine RTPCR test was positive (6). Given these premises, it is only intuitive to posit that especially anuric ESRD patients would arguably excrete less viral RNA in the urine and therefore could potentially retain COVID-19 RNA for longer.

Our knowledge base regarding COVID-19 continues to evolve. Our patient had persistently demonstrated positive nasopharyngeal RT-PCR tests for at least 22 days. This is about double the previously reported duration of such positive test results in a large cohort of inpatients from Shanghai, China (2). Finally, we surmise that the persistence of COVID-19 RNA in our patient may represent the syndrome of prolonged viral non-clearance which may be peculiar to especially anuric ESRD patients on maintenance hemodialysis. This may explain the recent repot of the surprising and unanticipated demonstration of a high rate of positive COVID-19 antibody testing among the staff of a Pediatric Outpatient Hemodialysis Unit in New York (7). Further studies are mandated as these investigations would help guide the implications of preventative measures against the spread of COVID-19 among both patients and staff of hemodialysis units around the world. If confirmed, this would lead to major paradigm shifts in the need for continued vigilance and infectious disease preventative measures to mitigate the spread of COVID-19 to both patients and staff within hemodialysis units around the world.

\section{Acknowledgements}

This work is dedicated to late Professor Wilson I.B. Onuigbo, former Professor of Pathology, at the University of Nigeria Teaching Hospital, Enugu, Nigeria. Professor W.I.B Onuigbo taught this author in medical school and worked with him in 1989 to describe the first published cases of multi-systemic vasculitis with renal involvement in Nigeria. The three cases were presented by this author to the West African College of Physicians in October 1989 as requirement for the dissertation for the award of the Fellowship of the West African College of Physicians in Nephrology (FWACP).

Author's contribution

MACO is the single author of the manuscript.

Conflicts of interest

The author declares that he has no conflict of interest. 


\section{Ethical considerations}

Ethical issues (including plagiarism, data fabrication, double publication) have been completely observed by the author.

\section{Funding/Support}

None.

\section{References}

1. Hirsch JS, Ng JH, Ross DW, Sharma P, Shah HH, Barnett RL et al. Acute kidney injury in patients hospitalized with COVID-19. Kidney Int. 2020;S0085-2538(20)30532-9. doi: 10.1016/j.kint.2020.05.006.

2. Ling Y, Xu S-B, Lin Y-X, Tian D, Zhu Z-Q, Dai F-H et al. Persistence and Clearance of Viral RNA in 2019 Novel Coronavirus Disease Rehabilitation Patients. Chin Med J (Engl). 2020;133:1039-43. doi: 10.1097/
CM9.0000000000000774.

3. https://www.cdc.gov/coronavirus/2019-ncov/hcp/dialysis/ dialysis-in-acute-care.html. Accessed May 12, 2020.

4. https://www.cdc.gov/coronavirus/2019-ncov/hcp/ disposition-hospitalized-patients.html. Accessed May 12, 2020.

5. Yu F, Yan L, Wang N, Yang S, Wang L, Tang Y et al. Quantitative detection and viral load analysis of SARSCoV-2 in infected patients. Clin Infect Dis. 2020; ciaa345. doi: $10.1093 / \mathrm{cid} / \mathrm{ciaa} 345$.

6. Ren J-G, Li D-Y, Wang C-F, Wu J-H, Wang Y, Sun Y-J. Positive RT-PCR in urine from an asymptomatic patient with novel coronavirus 2019 infection: a case report. Infect Dis (Lond). 2020. doi: 10.1080/23744235.2020.1766105.

7. Hains DS, Schwaderer AL, Carroll AE, Starr MC, Wislon AC, Amanat F, et al. Asymptomatic seroconversion of immunoglobulins to SARS-CoV-2 in a pediatric dialysis unit. JAMA. 2020;e208438. doi: 10.1001/jama.2020.8438.

Copyright (c) 2021 The Author(s); Published by Nickan Research Institute. This is an open-access article distributed under the terms of the Creative Commons Attribution License (http://creativecommons.org/licenses/by/4.0), which permits unrestricted use, distribution, and reproduction in any medium, provided the original work is properly cited. 